\title{
Short-term surgical outcomes from a phase III study of laparoscopy-assisted versus open distal gastrectomy with nodal dissection for clinical stage IA/IB gastric cancer: Japan Clinical Oncology Group Study JCOG0912
}

\author{
Hitoshi Katai ${ }^{1} \cdot$ Junki Mizusawa $^{2} \cdot$ Hiroshi Katayama $^{2} \cdot$ Masakazu Takagi $^{3} \cdot$ Takaki Yoshikawa $^{4} \cdot$ \\ Takeo Fukagawa $^{1} \cdot$ Masanori Terashima $^{5} \cdot$ Kazunari Misawa $^{6} \cdot$ Shin Teshima $^{7} \cdot$ Keisuke Koeda $^{8} \cdot$ \\ Souya Nunobe $^{9} \cdot$ Norimasa Fukushima $^{10} \cdot$ Takashi Yasuda $^{11} \cdot$ Yoshito Asao $^{12} \cdot$ Yoshiyuki Fujiwara $^{13}$. $^{1}$ \\ Mitsuru Sasako ${ }^{14}$
}

Received: 21 June 2016/ Accepted: 22 September 2016/Published online: 7 October 2016

(c) The International Gastric Cancer Association and The Japanese Gastric Cancer Association 2016

\begin{abstract}
Backgrounds No confirmatory randomized controlled trials (RCTs) have evaluated the efficacy of laparoscopy-assisted distal gastrectomy (LADG) compared with open distal gastrectomy (ODG). We performed an RCT to confirm that LADG is not inferior to ODG in efficacy.

Methods We conducted a multi-institutional RCT. Eligibility criteria included histologically proven gastric adenocarcinoma in the middle or lower third of the stomach, clinical stage I tumor. Patients were preoperatively randomized to ODG or LADG. This study is now in the follow-up stage. The primary endpoint is relapse-free survival (RFS) and the primary analysis is planned in 2018. Here, we compared the surgical outcomes of the two groups. This
\end{abstract}

This article was written by the authors on behalf of the Stomach Cancer Study Group of the Japan Clinical Oncology Group.

Hitoshi Katai

hkatai@ncc.go.jp

1 Gastric Surgery Division, National Cancer Center Hospital, 5-1-1 Tsukiji, chuo-ku, Tokyo 104-0045, Japan

2 Japan Clinical Oncology Group Data Center/Operations Office, National Cancer Center, Tokyo, Japan

3 Department of Gastroenterological Surgery, Shizuoka General Hospital, Shizuoka, Japan

4 Department of Gastrointestinal Surgery, Kanagawa Cancer Center Hospital, Yokohama, Japan

5 Division of Gastric Surgery, Shizuoka Cancer Center, Shizuoka, Japan

6 Department of Gastroenterological Surgery, Aichi Cancer Center Hospital, Nagoya, Japan

7 Department of Surgery, National Hospital Organization, Sendai Medical Center, Sendai, Japan trial was registered at the UMIN Clinical Trials Registry as UMIN000003319.

Results Between March 2010 and November 2013, 921 patients (LADG 462, ODG 459) were enrolled from 33 institutions. Operative time was longer in LADG than in ODG (median 278 vs. $194 \mathrm{~min}, p<0.001$ ), while blood loss was smaller (median 38 vs. $115 \mathrm{ml}, p<0.001$ ). There was no difference in the overall proportion with in-hospital grade 3-4 surgical complications (3.3\%: LADG, $3.7 \%$ : ODG). The proportion of patients with elevated serum AST/ALT was higher in LADG than in ODG (16.4 vs. $5.3 \%, p<0.001)$. There was no operation-related death in either arm.

Conclusions This trial confirmed that LADG was as safe as ODG in terms of adverse events and short-term clinical outcomes. LADG may be an alternative procedure in clinical IA/IB gastric cancer if the noninferiority of LADG in terms of RFS is confirmed.

8 Department of Surgery, Iwate Medical University, Morioka, Japan

9 Department of Gastroenterological Surgery, Cancer Institute Hospital, Tokyo, Japan

10 Department of Surgery, Yamagata Prefectural Central Hospital, Yamagata, Japan

11 Department of Gastroenterological Surgery, Hyogo Cancer Center, Akashi, Japan

12 Department of Gastroenterological Surgery, Tenri Hospital, Tenri, Japan

13 Department of Gastroenterological Surgery, Osaka Medical Center for Cancer and Cardiovascular Diseases, Osaka, Japan

14 Division of Upper Gastrointestinal Surgery, Department of Surgery, Hyogo College of Medicine, Nishinomiya, Japan 
Keywords Gastric cancer - Laparoscopic surgery . Gastrectomy $\cdot$ Clinical trial $\cdot$ Phase III

\section{Introduction}

The number of patients undergoing laparoscopy-assisted distal gastrectomy (LADG) has been increasing worldwide, even in countries in which it is used relatively rarely. However, its oncological efficiency can be questioned considering the biological behavior of this cancer (including frequent lymph node metastases, extranodal spread, and peritoneal dissemination), which is rather different from the behavior of colorectal cancer. Although some small-scale randomized controlled trials (RCTs) have suggested that LADG shows high efficacy [1-4], there has been no pivotal trial so far. In order to justify the use of a laparoscopic approach to gastric cancer, we started clinical trials targeting early-stage disease with low probabilities of nodal, extranodal, and peritoneal metastasis on the assumption that we should not apply this technique to more advanced disease if we could not show that LADG is not inferior to ODG.

We first conducted a multi-institutional phase II trial of LADG (JCOG0703) with 173 patients who had gastric cancer of clinical stage IA (T1N0) or IB (T1N1, T2N0) [5]. The primary endpoint was the incidence of postoperative anastomotic leak or pancreatic fistula, which was far lower $(1.7 \%)$ than the prespecified threshold $(8 \%)$. The overall proportion with in-hospital grade 3 or 4 adverse events was as low as $5.1 \%$. We concluded that LADG could be safely performed by credentialed surgeons.

We then launched this phase III trial (JCOG0912) to check for the noninferiority of LADG to ODG in terms of relapse-free survival (RFS) in all randomized patients with clinical IA/IB gastric cancer. The patient enrollment was completed, so we present the short-term surgical outcomes in this paper. We also compared them with recently published early results of a large-scale RCT with a similar design that was conducted in Korea (KLASS-1) [6].

\section{Methods}

\section{Study design}

This open-label, multi-institutional, randomized, two-arm (ODG and LADG) phase III trial is being conducted within the framework of the JCOG Stomach Cancer Study Group. The trial was designed to demonstrate that LADG is noninferior to ODG in terms of RFS. Only surgeons specializing in both procedures at 33 Japanese institutions are participating in the study. The study protocol was approved by the Protocol Review Committee of the JCOG and was approved and overseen by the institutional review board of each participating hospital. The design of the trial was reported previously [7].

\section{Participants}

Patients with a distal gastrectomy treatable, histologically proven gastric adenocarcinoma in the middle or lower third of the stomach, a c-stage IA (T1N0) or IB (T1N1, T2[MP]N0) tumor according to the 13th Japanese Classification of Gastric Carcinoma (corresponding to the 2nd English edition [8]) and no indications for endoscopic mucosal resection (EMR) or endoscopic submucosal dissection (ESD) were initially eligible for this study.

$\mathrm{T}$ category was evaluated by upper gastrointestinal endoscopy. Multidetector CT was used to diagnose T category and $\mathrm{N}$ category.

The detailed eligibility criteria for the study are shown in Table 1. All patients gave their written informed consent.

\section{Randomization and masking}

Randomization and data handling were performed by the JCOG Data Center. After confirming the eligibility criteria and receiving written informed consent, staff members registered patients by telephone, fax, or a web-based system with the JCOG Data Center. Patients were randomized to either the ODG arm or the LADG arm; the minimization method with a random component was used to balance the arms with respect to institution and clinical stage (IA/IB). The allocated procedure was not masked from investigators or patients.

\section{Procedures}

ODG and LADG were performed in their respective arms. All procedures were identical except for the surgical approach. The extent of nodal dissection was selected according to the surgical $\mathrm{T}$ and $\mathrm{N}$ stages, which were based on the third version of the Gastric Cancer Treatment Guidelines in Japan [9]. D1, D1+, or D2 dissection was applied for clinical stage IA tumors, while D2 dissection was performed for clinical stage IB tumors. For clinical T1 gastric cancer with margins that were $4 \mathrm{~cm}$ or further from the pylorus, pylorus-preserving distal gastrectomy was allowed. Bursectomy was not allowed, but preservation of the omentum and/or vagus nerve was discretionary. The reconstruction method was not specified in this study.

In the LADG arm, the mini-laparotomy incision was required to be shorter than $6 \mathrm{~cm}$. If the intraoperative findings revealed a tumor stage of II or greater, the LADG was converted to open surgery. We did not make any other 
Table 1 Eligibility criteria

\begin{tabular}{|c|c|}
\hline Inclusion criteria & Exclusion criteria \\
\hline 1. Histologically proven gastric adenocarcinoma & $\begin{array}{l}\text { 1. Synchronous or metachronous (within } 5 \text { years) } \\
\text { malignancies other than carcinoma in situ }\end{array}$ \\
\hline $\begin{array}{l}\text { 2. Clinical stage IA (T1N0) or IB (T1N1, T2[MP]N0) according to the Japanese } \\
\text { Classification of Gastric Carcinoma, second English edition [1] }\end{array}$ & 2. Infectious disease requiring systemic therapy \\
\hline $\begin{array}{l}\text { 3. In cases without preceding endoscopic mucosal resection (EMR) or endoscopic } \\
\text { submucosal dissection (ESD), both 'cN1' and 'cN0 and no indication of EMR or } \\
\text { ESD' are eligible }\end{array}$ & 3. Body temperature of $38^{\circ} \mathrm{C}$ or more \\
\hline $\begin{array}{l}\text { 4. In cases with preceding EMR or ESD, the following conditions are fulfilled: (1) } \\
\text { pathological findings require additional gastrectomy, (2) performed within } 91 \text { days } \\
\text { of EMR or ESD, (3) with no perforation by EMR or ESD, and (4) resection } \\
\text { margins of EMR or ESD do not reach the upper third of the stomach }\end{array}$ & 4. Women during pregnancy or breast-feeding \\
\hline $\begin{array}{l}\text { 5. Tumor located in the middle or lower third of the stomach, and curative resection is } \\
\text { expected to be achievable by distal gastrectomy }\end{array}$ & 5. Severe mental disease \\
\hline 6. No invasion to the duodenum & 6. Continuous systemic steroid therapy \\
\hline 7. Aged $20-80$ years & $\begin{array}{l}\text { 7. Unstable angina pectoris or history of myocardial } \\
\text { infarction within } 6 \text { months }\end{array}$ \\
\hline 8. Performance status (Eastern Cooperative Oncology Group) of 0 or 1 & 8. Uncontrollable hypertension \\
\hline 9. A body mass index of $<30$ & $\begin{array}{l}\text { 9. Uncontrollable diabetes mellitus or administration of } \\
\text { insulin }\end{array}$ \\
\hline 10. No history of upper abdominal surgery and no history of intestinal resection & $\begin{array}{l}\text { 10. Severe respiratory disease requiring continuous } \\
\text { oxygen therapy }\end{array}$ \\
\hline \multicolumn{2}{|l|}{$\begin{array}{l}\text { 11. No prior treatment of chemotherapy or radiation therapy against any other } \\
\text { malignancies }\end{array}$} \\
\hline \multicolumn{2}{|l|}{ 12. Sufficient organ function } \\
\hline 13. Written informed consent & \\
\hline
\end{tabular}

rules for conversion aside from this rule because the proportion of LADGs that were converted to open surgery was one of the secondary endpoints. When intraoperative difficulties were determined by credentialed surgeons as described below, the LADG was also converted to open surgery.

Postoperative analgesia, such as epidural anesthesia, was not specified. Usage of analgesics on postoperative days 5-10 was recorded. Adjuvant chemotherapy with S-1 for 1 year was recommended for patients with curative resection and a pathological stage II, IIIA, or IIIB tumor, excluding T1 disease.

Surgical quality control was facilitated by permitting only surgeons credentialed by the study chair to perform both LADG and ODG. In the ODG arm, only surgeons with experience of 60 or more open gastrectomies were credentialed. In the LADG arm, experience of 30 or more of both ODG and LADG procedures as well as certification (or its equivalent) by the Japan Society for Endoscopic Surgery were necessary. In arbitrarily selected cases, LADG procedures were centrally reviewed by photographs and by video. These photographs were evaluated by the committee for quality control and assessment of surgery, and problems regarding the surgical procedure were discussed at meetings held three times a year. To assess compliance with lymphadenectomy guidelines, the number of dissected nodes at all stations was recorded on case report forms and the results were monitored.

All enrolled patients were followed up at least every 6 months for the first 2 years and then every year for another 3 years until 5 years postoperatively. Tumor markers, chest X-ray, upper gastrointestinal endoscopy, and enhanced abdominal computed tomography were evaluated at least every year for the duration of follow-up. Operative methods and pathology results were recorded according to the 13th and 14th Japanese Classifications of Gastric Carcinoma, which correspond to the second and third English edition [8, 9]. Operating time, blood loss, and all postoperative morbidities during hospitalization were included on the case report forms for prospective data collection. Postoperative morbidity was described according to the Common Terminology Criteria for Adverse Events (CTCAE) ver. 4.0 and the JCOG postoperative complication criteria based on the Clavien-Dindo classification [10].

\section{Outcomes}

The primary endpoint of this study was RFS in all randomized patients. RFS was defined as days from 
randomization to relapse or death from any cause, and was censored at the most recent day when the patient was alive without any evidence of relapse. The secondary endpoints were overall survival (OS) in all randomized patients, proportion of LADGs that were completed, proportion of LADGs that were converted to open surgery, adverse events, short-term clinical outcomes, and postoperative quality of life (QOL). OS was defined as days from randomization to death from any cause, and was censored at the last day when the patient is alive. The proportion of LADGs that were completed was defined as the proportion of all operated patients in the LADG arm in whom LADG was completed without conversion to open surgery. The proportion of LADGs that were converted to open surgery was defined as the proportion of patients who underwent conversion from LADG to open surgery among those diagnosed before gastrectomy as clinical stage IA or IB. The short-term clinical outcomes consisted of: (1) the time from the end of surgery until the first episode of flatus, (2) the proportion of patients requiring an analgesic on postoperative days 5-10, (3) the highest body temperatures during the first 3 days after surgery, and (4) the highest body temperatures during hospitalization. Postoperative QOL was evaluated using EORTC QLQ-C30 and STO22. This QOL evaluation was performed only in the four principal institutions due to a lack of resources in the other institutions. The primary analysis of QOL was performed using the global health status from EORTC QLQ-C30 at the 90th postoperative day.

\section{Statistical analysis}

This randomized trial was designed to demonstrate that LADG is noninferior to ODG in terms of RFS. Some endpoints were adopted to evaluate whether LADG is less invasive than ODG, but these endpoints were all considered to be exploratory. Thus, as long as the noninferiority of LADG is confirmed, LADG may be considered an option for the standard treatment of clinical stage IA/IB gastric cancer.

The initial primary endpoint was OS. According to Schoenfeld and Richter's method [11], the planned sample size was 920 patients, with 460 patients per arm. We anticipated 5 years of follow-up after 5 years of accrual, ensuring at least $80 \%$ power with a one-sided alpha of $5 \%$ and a noninferiority margin of $5 \%$ in terms of 5 -year OS (a noninferiority margin for a hazard ratio of 1.54). This assumed an expected 5-year OS of $90 \%$ in each arm.

In April 2015, which was before the first interim analysis, the primary endpoint was amended from OS to RFS because the surrogacy of RFS was demonstrated in a metaanalysis [12] and the predicted number of events for OS was smaller than expected. After amending the primary endpoint, $68 \%$ power was maintained with a one-sided alpha of $5 \%$ and a noninferiority margin for a hazard ratio of 1.54 , which corresponds to $3.6 \%$ in terms of 5-year RFS.

Differences in proportions between arms were evaluated using Fisher's exact test. Comparisons of continuous data were performed using the Wilcoxon rank sum test. All $p$ values were two-sided at the $5 \%$ significance level, and because of the exploratory nature of the analysis, no adjustment for multiplicity was carried out.

To investigate the association between the proportion with surgical complications and BMI, the Cochran-Armitage trend test was used in each arm.

All statistical analysis was performed using SAS 9.2 (SAS Institute, Cary, NC, USA). The data presented in this article were as of December 2015. Analysis was performed per protocol set, including patients who received protocol treatments as assigned. This trial was registered at the UMIN Clinical Trials Registry as UMIN000003319 (http:// www.umin.ac.jp/ctr/index.htm).

We plan to conduct two interim analyses, taking multiplicity into account using the Lan-DeMets method with the O'Brien and Fleming-type alpha spending function [13]. The Data and Safety Monitoring Committee (DSMC) of the JCOG will independently review the interim analysis reports and will recommend early trial termination if necessary. In-house monitoring is performed every 6 months by the JCOG Data Center to evaluate and improve study progress, data integrity, and patient safety.

\section{Results}

Between March 2010 and November 2013, 921 patients (ODG 459, LADG 462) were enrolled from 33 institutions in Japan (Fig. 1). Among all of the randomized patients, 455 patients who underwent ODG and 457 patients who underwent LADG were analyzed for surgical outcome. In the ODG arm, two patients who withdrew their consent and two patients who refused the assigned surgery were excluded. In the LADG arm, five patients were excluded: one patient whose diagnosis of gastric cancer at a previous hospital was not confirmed at the participating hospital; one patient who was diagnosed preoperatively as having widespread cancer which required total gastrectomy; one patient whose surgery was canceled due to ischemic heart disease just after the operation started; and two patients who refused the assigned surgery.

Patient demographics are summarized in Table 2. Baseline factors were well balanced between the two arms. Surgical procedures and outcomes are summarized in Table 3. Distal gastrectomy was performed in 333 
Fig. 1 Trial profile

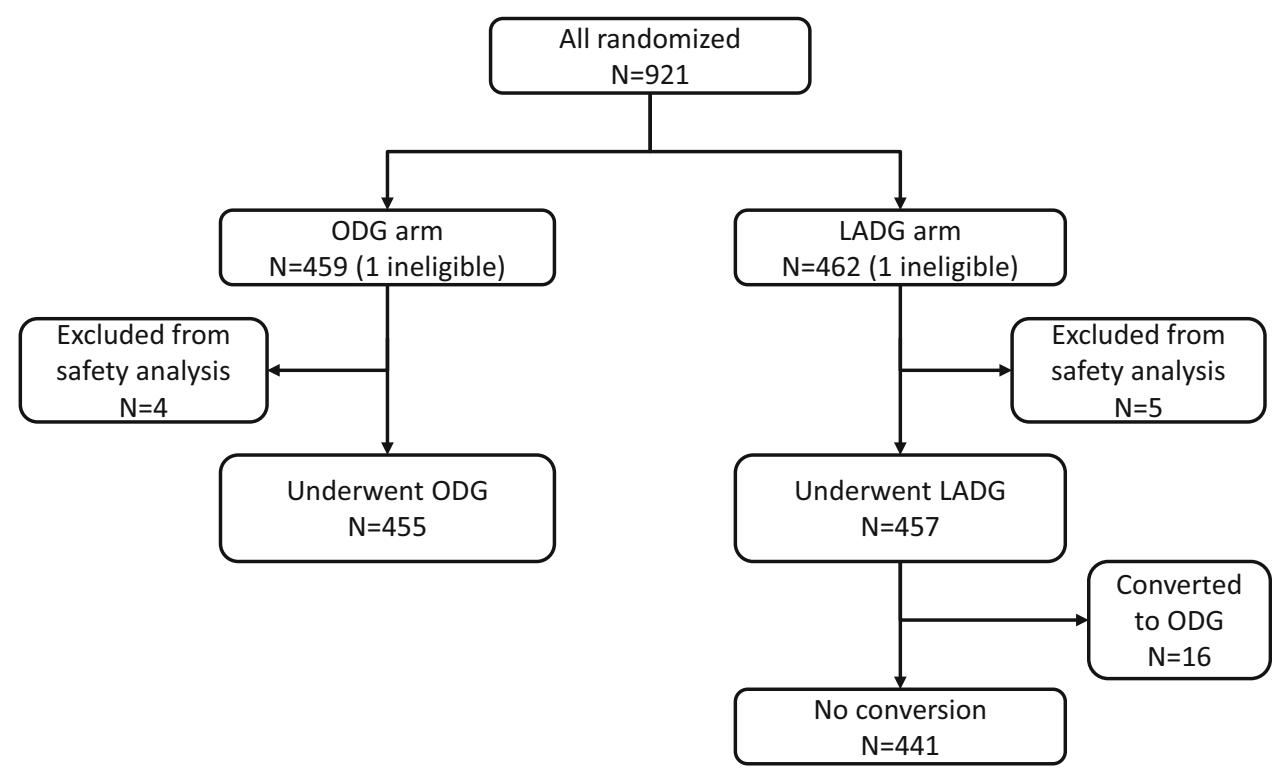

Table 2 Baseline characteristics

\begin{tabular}{|c|c|c|}
\hline & ODG $(n=459)$ & LADG $(n=462)$ \\
\hline Age, median & 64 & 63 \\
\hline$\left(\mathrm{IQR}^{\mathrm{a}}\right)$ & $(57-70)$ & $(58-69)$ \\
\hline (Range) & $(27-80)$ & $(25-80)$ \\
\hline \multicolumn{3}{|l|}{ Gender } \\
\hline Male & $275(59.9 \%)$ & $289(62.6 \%)$ \\
\hline Female & $184(40.1 \%)$ & $173(37.4 \%)$ \\
\hline \multicolumn{3}{|l|}{ Clinical T stage ${ }^{\mathrm{b}}$} \\
\hline $\mathrm{T} 1$ & $411(89.5 \%)$ & $411(89.0 \%)$ \\
\hline $\mathrm{T} 2$ & $48(10.5 \%)$ & $50(10.8 \%)$ \\
\hline Unknown & $0(0 \%)$ & $1(0.2 \%)$ \\
\hline \multicolumn{3}{|l|}{ Clinical N stage ${ }^{\mathrm{b}}$} \\
\hline No & $452(98.5 \%)$ & $451(97.6 \%)$ \\
\hline N1 & $7(1.5 \%)$ & $10(2.2 \%)$ \\
\hline Unknown & $0(0 \%)$ & $1(0.2 \%)$ \\
\hline \multicolumn{3}{|l|}{ Clinical stage $\mathrm{e}^{\mathrm{b}}$} \\
\hline IA & $404(88.0 \%)$ & $401(86.8 \%)$ \\
\hline IB & $55(12.0 \%)$ & $60(13.0 \%)$ \\
\hline Unknown & $0(0 \%)$ & $1(0.2 \%)$ \\
\hline \multicolumn{3}{|c|}{ ECOG performance status } \\
\hline 0 & $458(99.8 \%)$ & $459(99.4 \%)$ \\
\hline 1 & $1(0.2 \%)$ & $3(0.6 \%)$ \\
\hline BMI $\left(\mathrm{kg} / \mathrm{m}^{2}\right)$, median & 22.6 & 22.3 \\
\hline (IQR) & $(20.6-24.4)$ & $(20.6-24.4)$ \\
\hline (Range) & $(16.2-29.7)$ & $(15.2-28.5)$ \\
\hline$<20$ & $86(18.7 \%)$ & $94(20.3 \%)$ \\
\hline$\geq 20,<25$ & $283(61.7 \%)$ & $284(61.5 \%)$ \\
\hline$\geq 25$ & $90(19.6 \%)$ & $84(18.2 \%)$ \\
\hline
\end{tabular}

\footnotetext{
${ }^{a}$ Interquartile range

b The 13th Japanese Classification of Gastric Carcinoma, which corresponds to the second English edition
}

(73.2\%) patients in the ODG arm and $342(74.8 \%)$ patients in the LADG arm. Pylorus-preserving gastrectomy was performed in $122(26.8 \%)$ patients in the ODG arm and $114(24.9 \%)$ patients in the LADG arm. There was no difference in the distribution of operative methods between the two arms. D1+ was performed in $319(70.1 \%)$ patients in the ODG arm and 347 (75.9\%) patients in the LADG arm. D2 was performed in $126(27.7 \%)$ patients in the ODG arm and $101(22.1 \%)$ patients in the LADG arm. There was no difference in the distribution of the extent of nodal dissection between the two arms. Billroth I was performed in $211(46.4 \%)$ patients in the ODG arm and $221(48.4 \%)$ patients in the LADG arm. Roux-en-Y was performed in $119(26.2 \%)$ patients in the ODG arm and $121(26.5 \%)$ patients in the LADG arm. There was no difference in the distribution of reconstruction methods between the two arms.

Blood loss was smaller in LADG than in ODG [median (range), $38(0-1920) \mathrm{mL}$ vs. $115(0-890) \mathrm{mL}, p<0.001]$. Operative time was longer in LADG than ODG [median (range), 278 (120-577) $\mathrm{min}$ vs. 194 (48-445) $\mathrm{min}$, $p<0.001]$. Conversion to open surgery was necessary in $16(3.5 \%)$ patients, and these patients were included in the LADG arm.

The most common reasons for conversion were technical: bleeding [four patients $(25.0 \%)$ ], difficulty with gastric transection and reconstruction [three patients $(18.8 \%)$ ], torsion of the anastomosis [one patient (6.3\%)], inability to visualize the operative field [one patient $(6.3 \%)]$, and inadequate stapling of the duodenal stump [one patient $(6.3 \%)$ ]. Other reasons for conversion were nontechnical: intraoperative diagnosis of stage II or III tumors [four patients $(25 \%)$ ], inability to perform additional resection of the positive cut end [one patient 
Table 3 Operative details

\begin{tabular}{|c|c|c|c|}
\hline & ODG $(n=455)$ & LADG $(n=457)$ & $p$ value \\
\hline $\begin{array}{l}\text { Operative time (min), median } \\
\text { (IQR) } \\
\text { (Range) }\end{array}$ & $\begin{array}{l}194 \\
(159-235) \\
(48-445)\end{array}$ & $\begin{array}{l}278 \\
(230-327) \\
(120-577)\end{array}$ & $<0.001$ \\
\hline $\begin{array}{l}\text { Blood loss (ml), median } \\
\text { (IQR) } \\
\text { (Range) }\end{array}$ & $\begin{array}{l}115 \\
(60-225) \\
(0-890)\end{array}$ & $\begin{array}{l}38 \\
(17-90) \\
(0-1920)\end{array}$ & $<0.001$ \\
\hline \multicolumn{4}{|l|}{ Operative procedure } \\
\hline $\begin{array}{l}\text { Distal gastrectomy } \\
\text { Pylorus-preserving gastrectomy } \\
\text { Total gastrectomy }\end{array}$ & $\begin{array}{l}333(73.2 \%) \\
122(26.8 \%) \\
0(0 \%)\end{array}$ & $\begin{array}{l}342(74.8 \%) \\
114(24.9 \%) \\
1(0.2 \%)\end{array}$ & \\
\hline \multicolumn{4}{|l|}{ Extent of lymph node dissection } \\
\hline $\begin{array}{l}\text { D0 } \\
\text { D1 } \\
\text { D1+ } \\
\text { D2 } \\
\text { D2+ }\end{array}$ & $\begin{array}{l}0(0 \%) \\
5(1.1 \%) \\
319(70.1 \%) \\
126(27.7 \%) \\
5(1.1 \%)\end{array}$ & $\begin{array}{l}0(0 \%) \\
5(1.1 \%) \\
347(75.9 \%) \\
101(22.1 \%) \\
4(0.9 \%)\end{array}$ & \\
\hline \multicolumn{4}{|l|}{ Reconstruction method } \\
\hline $\begin{array}{l}\text { Roux-en-Y } \\
\text { Billroth I } \\
\text { Billroth II } \\
\text { Gastro-gastro }\end{array}$ & $\begin{array}{l}119(26.2 \%) \\
211(46.4 \%) \\
3(0.7 \%) \\
122(26.8 \%)\end{array}$ & $\begin{array}{l}121(26.5 \%) \\
221(48.4 \%) \\
1(0.2 \%) \\
114(24.9 \%)\end{array}$ & \\
\hline $\begin{array}{l}\text { Length of skin incision }(\mathrm{cm}) \text {, median } \\
\text { (IQR) } \\
\text { (Range) }\end{array}$ & $\begin{array}{l}16 \\
(14.0-18.0) \\
(4.0-25.0)\end{array}$ & $\begin{array}{l}5 \\
(4.5-5.7) \\
(1.0-23.0)\end{array}$ & \\
\hline Conversion & - & $16(3.5 \%)$ & \\
\hline
\end{tabular}

Table 4 Short-term clinical outcomes

\begin{tabular}{llll}
\hline & ODG $(n=455)$ & LADG $(n=457)$ & \\
\hline First flatus, P.O.D. ${ }^{a}$ median & 3 & 2 & $<0.001$ \\
(IQR) & $(2-3)$ & $(0-7)$ & \\
(Range) & $(0-13)$ & $230(50.3 \%)$ \\
Proportion who required analgesics on P.O.D. 5-10 & $270(59.3 \%)$ & $37.9(37.5-38.2)$ \\
The highest body temperature during hospital stay (IQR) & $37.8(37.5-38.2)$ & $37.8(37.4-38.1)$ & 0.006 \\
P.O.D. 1 & $37.7(36.2-39.4)$ & $37.3(37.0-37.7)$ & 0.34 \\
P.O.D. 2 & $37.3(37.0-37.7)$ & $37.0(36.8-37.3)$ \\
P.O.D. 3 & $37.0(36.8-37.3)$ & $2(0.4 \%)$ & 0.36 \\
Reoperation & $2(0.4 \%)$ & $3(0.7 \%)$ \\
Red blood cell transfusion during hospital stay & $1(0.2 \%)$ & 0.80 \\
Operation-related death & 0 & 1.00
\end{tabular}

${ }^{a}$ Postoperative day

$(6.3 \%)]$, and anomalous common hepatic artery and left gastric artery [one patient $(6.3 \%)$ ].

There were no grade 3 or 4 intraoperative adverse events in either arm.

Regarding postoperative recovery, laparoscopic surgery was associated with a shorter time to first flatus [median (range), 2 (0-7) days vs. 3 (0-13) days, $p<0.001$ ] (Table 4).
There was no difference between the arms in either the highest body temperatures during the first 3 days postoperatively or the highest body temperatures during hospitalization. The use of analgesics after 5 postoperative days was more frequent in the open surgery arm than in the laparoscopic surgery arm [270 $(59.3 \%)$ patients with open surgery vs. $230(50.3 \%)$ patients with laparoscopic surgery, $p=0.006]$. 
Table 5 Histological findings

\begin{tabular}{|c|c|c|}
\hline & $\begin{array}{l}\text { ODG } \\
(n=455)\end{array}$ & $\begin{array}{l}\text { LADG } \\
(n=457)\end{array}$ \\
\hline Tumor size $(\mathrm{cm})$, median & 2.5 & 2.7 \\
\hline (IQR) & $(2.0-3.5)$ & $(2.0-3.7)$ \\
\hline (Range) & $(0.7-20.0)$ & $(0.6-28.0)$ \\
\hline \multicolumn{3}{|l|}{ Histological type } \\
\hline Pap & $4(0.9 \%)$ & $7(1.5 \%)$ \\
\hline Tub1 & $85(18.7 \%)$ & $86(18.8 \%)$ \\
\hline Tub2 & $100(22.0 \%)$ & $113(24.7 \%)$ \\
\hline Por & $153(34.1 \%)$ & $141(30.9 \%)$ \\
\hline Sig & $109(24.0 \%)$ & $103(22.5 \%)$ \\
\hline Muc & $1(0.2 \%)$ & $0(0 \%)$ \\
\hline Others & $3(0.7 \%)$ & $7(1.5 \%)$ \\
\hline \multicolumn{3}{|l|}{$\mathrm{T}$ stage } \\
\hline T1a & $201(44.2 \%)$ & $217(47.5 \%)$ \\
\hline $\mathrm{T} 1 \mathrm{~b}$ & $197(43.3 \%)$ & $173(37.9 \%)$ \\
\hline $\mathrm{T} 2$ & $33(7.3 \%)$ & $50(10.9 \%)$ \\
\hline $\mathrm{T} 3$ & $19(4.2 \%)$ & $12(2.6 \%)$ \\
\hline $\mathrm{T} 4 \mathrm{a}$ & $5(1.1 \%)$ & $4(0.9 \%)$ \\
\hline $\mathrm{T} 4 \mathrm{~b}$ & $0(0 \%)$ & $0(0 \%)$ \\
\hline $\mathrm{TX}$ & $0(0 \%)$ & $1(0.2 \%)$ \\
\hline \multicolumn{3}{|l|}{$\mathrm{N}$ stage (13th) } \\
\hline N0 & $395(86.8 \%)$ & $395(86.4 \%)$ \\
\hline N1 & $42(9.2 \%)$ & $49(10.7 \%)$ \\
\hline $\mathrm{N} 2$ & $17(3.7 \%)$ & $13(2.8 \%)$ \\
\hline N3 & $1(0.2 \%)$ & $0(0 \%)$ \\
\hline \multicolumn{3}{|l|}{$\mathrm{N}$ stage (14th) } \\
\hline No & $395(86.8 \%)$ & $395(86.4 \%)$ \\
\hline N1 & $40(8.8 \%)$ & $40(8.8 \%)$ \\
\hline $\mathrm{N} 2$ & $11(2.4 \%)$ & $13(2.8 \%)$ \\
\hline N3a & $7(1.5 \%)$ & $5(1.1 \%)$ \\
\hline $\mathrm{N} 3 \mathrm{~b}$ & $2(0.4 \%)$ & $4(0.9 \%)$ \\
\hline pH1 & $0(0 \%)$ & $0(0 \%)$ \\
\hline pP1 & $0(0 \%)$ & $0(0 \%)$ \\
\hline \multicolumn{3}{|l|}{ Lavage cytology } \\
\hline CY0 & $267(58.7 \%)$ & $120(26.3 \%)$ \\
\hline CY1 & $0(0 \%)$ & $0(0 \%)$ \\
\hline CYX & $188(41.3 \%)$ & $337(73.7 \%)$ \\
\hline \multicolumn{3}{|l|}{ Proximal margin } \\
\hline PM0 & $454(99.8 \%)$ & $457(100 \%)$ \\
\hline PM1 & $1(0.2 \%)$ & $0(0 \%)$ \\
\hline PMX & $0(0 \%)$ & $0(0 \%)$ \\
\hline \multicolumn{3}{|l|}{ Distal margin } \\
\hline DM0 & $455(100 \%)$ & $456(99.8 \%)$ \\
\hline DM1 & $0(0 \%)$ & $1(0.2 \%)$ \\
\hline DMX & $0(0 \%)$ & $0(0 \%)$ \\
\hline \multicolumn{3}{|l|}{$\mathrm{R}$ classification } \\
\hline $\mathrm{R} 0$ & $454(99.8 \%)$ & $456(99.8 \%)$ \\
\hline $\mathrm{R} 1$ & $1(0.2 \%)$ & $1(0.2 \%)$ \\
\hline
\end{tabular}

Table 5 continued

\begin{tabular}{lll}
\hline & $\begin{array}{l}\text { ODG } \\
(n=455)\end{array}$ & $\begin{array}{l}\text { LADG } \\
(n=457)\end{array}$ \\
\hline R2 & $0(0 \%)$ & $0(0 \%)$ \\
RX & $0(0 \%)$ & $0(0 \%)$ \\
Stage (13th) & & \\
IA & $364(80.0 \%)$ & $354(77.5 \%)$ \\
IB & $52(11.4 \%)$ & $67(14.7 \%)$ \\
II & $28(6.2 \%)$ & $30(6.6 \%)$ \\
IIIA & $10(2.2 \%)$ & $6(1.3 \%)$ \\
IIIB & $0(0 \%)$ & $0(0 \%)$ \\
IV & $1(0.2 \%)$ & $0(0 \%)$ \\
Stage (14th) & & \\
IA & $364(80.0 \%)$ & $354(77.5 \%)$ \\
IB & $47(10.3 \%)$ & $58(12.7 \%)$ \\
IIA & $20(4.4 \%)$ & $22(4.8 \%)$ \\
IIB & $11(2.4 \%)$ & $16(3.5 \%)$ \\
IIIA & $8(1.8 \%)$ & $6(1.3 \%)$ \\
IIIB & $4(0.9 \%)$ & $1(0.2 \%)$ \\
IIIC & $0(0 \%)$ & $0(0 \%)$ \\
IV & $1(0.2 \%)$ & $0(0 \%)$ \\
Number of harvested lymph nodes, & 39 & 39 \\
median & & \\
(IQR) & $(30-48)$ & $(31-49)$ \\
(Range) & $(11-114)$ & $(8-94)$ \\
Number of metastatic lymph nodes, & 0 & 0 \\
(IQR) & $(0-0)$ & $(0-0)$ \\
(Range) & $(0-19)$ & $(0-42)$ \\
\hline & & \\
\hline
\end{tabular}

There was no marked difference between the two approaches regarding the incidence of reoperation. In the ODG arm, reoperation was performed in two patients because of one case of delayed gastric emptying and one case of intestinal strangulation. In the LADG arm, reoperation was performed in two patients: one because of bowel obstruction and the other because of postoperative bleeding. Red blood cell transfusion was required in one patient in the ODG arm and three patients in the LADG arm. There was no obvious difference regarding the proportion of the patients who required blood transfusion. There were no operation-related deaths in either arm.

Pathological data are summarized in Table 5. There were no marked differences in pathological data between the two arms. The proximal resection margin was positive in one patient in the ODG arm and the distal resection margin was positive in one patient in the LADG arm; both of these patients received additional resection as postprotocol treatment. The number of harvested lymph nodes did not differ between the two arms. 
Table 6 In-hospital grade 3-4 nonhematological and hematological adverse events

\begin{tabular}{|c|c|c|c|}
\hline CTCAE v4.0 & ODG $(n=455)$ & LADG $(n=457)$ & $p$ value \\
\hline \multicolumn{4}{|l|}{ Nonhematological surgical } \\
\hline Overall & $17(3.7 \%)$ & $15(3.3 \%)$ & 0.72 \\
\hline Pancreatic fistula & $2(0.4 \%)$ & $2(0.4 \%)$ & 1.00 \\
\hline Anastomotic leak & $1(0.2 \%)$ & $1(0.2 \%)$ & 1.00 \\
\hline Intraabdominal abscess & $8(1.8 \%)$ & $7(1.5 \%)$ & 0.80 \\
\hline Postoperative hemorrhage & 0 & $2(0.4 \%)$ & 0.50 \\
\hline Anastomotic stenosis & 0 & 0 & \\
\hline Cholecystitis & 0 & 0 & \\
\hline Dumping syndrome & 0 & 0 & \\
\hline Delayed gastric emptying & $4(0.9 \%)$ & $3(0.7 \%)$ & 0.73 \\
\hline Gastroesophageal regurgitation & 0 & 0 & \\
\hline Bowel obstruction & $1(0.2 \%)$ & $1(0.2 \%)$ & 1.00 \\
\hline Ileus & 0 & 0 & \\
\hline Thromboembolic event & 0 & 0 & \\
\hline Pneumonia & $4(0.9 \%)$ & $1(0.2 \%)$ & 0.22 \\
\hline Chyle leakage & 0 & 0 & \\
\hline Wound infection & 0 & $2(0.4 \%)$ & 0.50 \\
\hline Wound dehiscence & $1(0.2 \%)$ & 0 & 0.50 \\
\hline \multicolumn{4}{|l|}{ Nonhematological nonsurgical } \\
\hline Hypoalbuminemia & $1(0.2 \%)$ & $1(0.2 \%)$ & 1.00 \\
\hline Hyperbilirubinemia & $4(0.9 \%)$ & $2(0.4 \%)$ & 0.45 \\
\hline AST/ALT increased & $24(5.3 \%)$ & $75(16.4 \%)$ & $<0.001$ \\
\hline Creatinine increased & 0 & 0 & \\
\hline Hypernatremia & 0 & 0 & \\
\hline Hyponatremia & $5(1.1 \%)$ & $3(0.7 \%)$ & 0.51 \\
\hline Hyperkalemia & $2(0.4 \%)$ & 0 & 0.25 \\
\hline Hypokalemia & $2(0.4 \%)$ & 0 & 0.25 \\
\hline \multicolumn{4}{|l|}{ Hematological } \\
\hline Leukopenia & 0 & 0 & \\
\hline Anemia & $5(1.1 \%)$ & $6(1.3 \%)$ & 1.00 \\
\hline Thrombocytopenia & 0 & $1(0.2 \%)$ & 1.00 \\
\hline
\end{tabular}

Table 6 summarizes in-hospital grade 3-4 adverse events. There was no difference in the overall proportion with in-hospital grade 3-4 surgical complications [17 (3.7 \%): ODG vs. 15 (3.3\%): LADG] or the mortality rate (no patient in either arm).

The proportion with grade 3-4 surgical complications was $0 \%(0 / 84)(\mathrm{BMI}<20), 4.6 \%(123 / 281) \quad(\mathrm{BMI} \geq 20$, $<25)$, and $4.4 \%(4 / 90)(B M I \geq 25)$ in the ODG arm. The proportion with grade 3-4 surgical complications was $2.1 \%(2 / 94)$ (BMI <20), $2.1 \%(6 / 280)$ (BMI $\geq 20,<25)$, and $8.4 \%(7 / 83)(B M I \geq 25)$ in the LADG arm. In the ODG arm, the proportion with surgical complications did not increase with increasing BMI ( $p=0.066)$. However, in the LADG arm, the proportion with surgical complications increased with increasing BMI $(p=0.012)$.

The proportion with grade 3 or 4 serum AST/ALT elevation was significantly higher in LADG than in ODG (16.4 vs. $5.3 \%, p<0.001$ ).

\section{Discussion}

This study demonstrated good short-term clinical outcomes in both arms, such as no intraoperative complications, a low proportion of postoperative complications, and favorable postoperative recovery. The same surgical procedures were used in the LADG and ODG arms, such as extent of lymph node dissection and reconstruction methods, but patients undergoing LADG experienced longer operative times and less blood loss. The overall proportion with inhospital postoperative complications was quite low in both arms, but the proportion with elevated AST/ALT levels was higher in LADG than in ODG. The most plausible reason for this difference was the prolonged liver retraction during LADG. In laparoscopic surgery, the liver was generally retracted for the full duration of the operation, whereas in open surgery, retraction was performed only when needed. Other reasons could be longer operative 
times, pneumoperitoneum (which may reduce portal vein circulation), and the method of liver retraction.

Surgeons should try to reduce the duration of liver retraction. Moving the position of the retractor or releasing it intermittently may be an effective method of preventing postoperative liver damage [14]. Instead of employing mechanical surgical liver retractors, applying elastic retraction (e.g., utilizing a Penrose drain) might be useful [15].

Recent studies focusing on LADG have shown that a high BMI does not increase the likelihood of surgical complications [16-18]. In this study, in the LADG arm, the proportion with surgical complications increased with increasing BMI, even though only credentialed surgeons performed the surgery. However, the number of patients with complications was too small to allow us to draw any conclusions.

Regarding postoperative recovery, LADG was associated with a shorter time to pass first flatus and less use of analgesics after 5 postoperative days. This study demonstrated favorable postoperative recovery from laparoscopic surgery.

As for conversion from LADG to ODG, the conversion rate of $3.5 \%$ was similar to that seen in JCOG0703 [2], but higher than that noted in previous reports by Kim et al. $(0.2 \%)$ [19], Lee (1.7\%) [20], and Kim (0.9\%) [6]. A potential reason for the higher conversion rate observed in this study is that our protocol required intraoperative conversion to open surgery when the tumor was intraoperatively diagnosed as stage IB (T2[SS]N0), II, IIIA, or IIIB. In addition, conversion to open surgery was carried out for other nontechnical reasons such as a secure surgical margin and an anatomic anomaly, because the surgeons wanted to achieve the same quality of surgery as obtained with ODG, as the guidelines [1] that we used clearly state that LADG is still an investigational treatment. If these 6 cases are excluded, the proportion for whom technical conversion was performed was $2.2 \%$, close to the proportions seen in previous studies. Among these technical conversions, conversion due to difficulty with reconstruction might have been avoided by introducing intracorporeal anastomosis, but it was still a demanding procedure during this study period. We consider that the conversion rate of our trial was acceptable because this was a multicenter trial.

In South Korea, an RCT named KLASS-01 [6] was started prior to this study (JCOG0912) to compare LADG with ODG in a noninferiority design. The Korean trial is also at the follow-up stage as of 2015. The morbidity and mortality in KLASS-01 have already been reported. There are some differences between JCOG0912 and KLASS-01. First, the number of retrieved lymph nodes was comparable for the LADG and ODG groups in JCOG0912 butwas smaller in the LADG arm than in the ODG arm in KLASS01. Second, in JCOG0912, the proportion of postoperative complications was similarly low in the LADG and ODG arms, whereas postoperative morbidity was higher in the ODG arm than in the LADG arm in KLASS-01. Third, the number of ineligible patients and those who did not receive the assigned surgery was much smaller in JCOG0912 than in KLASS-01.

Two patients $(0.2 \%)$ withdrew their consent in JCOG0912, while 18 patients $(1.3 \%)$ withdrew their consent in KLASS-01. Among all of the eligible patients, three patients $(0.3 \%)$ switched from ODG to LADG or from LADG to ODG in JCOG0912, while 85 (6.1\%) patients switched from ODG to LADG or from LADG to ODG in KLASS-01. One $(0.1 \%)$ patient switched to total gastrectomy in JCOG0912, while 23 patients (1.7\%) switched to total gastrectomy in KLASS-01.

As a result, safety was analyzed in a higher proportion of patients in JCOG0912 (99.0\%) than in KLASS-01 $(88.7 \%)$. In addition, the higher proportion who underwent a procedural switch in KLASS-01 could have a significant influence, especially in noninferiority trials. Such contaminations generally attenuate the survival difference; the results of noninferiority trials could be positive even when LADG is actually inferior to ODG. From this statistical point of view, it should be noted that the efficacy results for KLASS-01 have some limitations, and any definitive conclusion should be drawn based on the results of both JCOG0912 and KLASS-01. There are four potential reasons for this discrepancy. First, our JCOG Stomach Cancer Group has recognized the importance of maintaining clinical trial quality and has become proficient at clinical trials since this group started in 1995. Second, to ensure the quality of our trial, in-house monitoring was performed every 6 months by the JCOG Data Center. Third, regular group meetings were held to share information on ineligible patients. Fourth, the Japanese treatment guidelines specify that ODG is the standard procedure and LADG is an investigational treatment, and the documents given to patients prior to them providing informed consent conformed strictly with these guidelines. Therefore, the patients generally understood these circumstances.

In conclusion, although the elevation of serum AST/ ALT should be addressed, this trial confirmed that LADG performed by credentialed surgeons is as safe as ODG in terms of adverse events and short-term clinical outcomes. LADG may be an alternate procedure for clinical IA/IB gastric cancer if the noninferiority of LADG in RFS is confirmed by the primary analysis planned in 2018 .

Funding The study was supported in part by National Cancer Center Research and Development Funds (23-A-16, 23-A-19, 26-A-4), Grants-in-Aid for Clinical Cancer Research (H21-019, H24-09), and a Health Science Research Grant for Medical Frontier Strategy Research (H26-053) from the Ministry of Health, Labour and Welfare of Japan. 
Conflict of interest We declare that we have no conflicts of interest.

Human rights statement and informed consent All procedures followed were in accordance with the ethical standards of the responsible committee on human experimentation (institutional and national) and with the Helsinki Declaration of 1964 and later versions. Informed consent or a substitute for it was obtained from all patients before they were included in the study.

\section{References}

1. Kitano S, Shiraishi N, Fujii K, Yasuda K, Inomata M, Adachi Y. A randomized controlled trial comparing open vs laparoscopyassisted distal gastrectomy for the treatment of early gastric cancer: an interim report. Surgery. 2002;131(1 Suppl):S306-11.

2. Hayashi H, Ochiai T, Shimada H, Gunji Y. Prospective randomized study of open versus laparoscopy-assisted distal gastrectomy with extraperigastric lymph node dissection for early gastric cancer. Surg Endosc. 2005;19(9):1172-6.

3. Lee JH, Han HS, Lee JH. A prospective randomized study comparing open vs laparoscopy-assisted distal gastrectomy in early gastric cancer: early results. Surg Endosc. 2005;19(2): $168-73$.

4. Kim YW, Baik YH, Yun YH, Nam BH, Kim DH, Choi IJ, et al. Improved quality of life outcomes after laparoscopy-assisted distal gastrectomy for early gastric cancer: results of a prospective randomized clinical trial. Ann Surg. 2008;248(5):721-7.

5. Katai H, Sasako M, Fukuda H, Nakamura K, Hiki N, Saka M, et al. Safety and feasibility of laparoscopy-assisted distal gastrectomy with suprapancreatic nodal dissection for clinical stage I gastric cancer: a multicenter phase II trial (JCOG 0703). Gastric Cancer. 2010;13(4):238-44.

6. Kim W, Kim HH, Han SU, Kim MC, Hyung WJ, Ryu SW, et al. Decreased morbidity of laparoscopic distal gastrectomy compared with open distal gastrectomy for stage I gastric cancer: short-term outcomes from a multicenter randomized controlled trial (KLASS-01). Ann Surg. 2016;263(1):28-35.

7. Nakamura K, Katai H, Mizusawa J, Yoshikawa T, Ando M, Terashima M, et al. A phase III study of laparoscopy-assisted versus open distal gastrectomy with nodal dissection for clinical stage IA/IB gastric cancer (JCOG0912). Jpn J Clin Oncol. 2013;43(3):324-7.

8. Japanese Gastric Cancer Association. Japanese classification of gastric carcinoma-2nd English edition. Gastric Cancer. 1998;1(1): $10-24$.
9. Japanese Gastric Cancer Association. Japanese gastric cancer treatment guidelines 2010 (ver. 3). Gastric Cancer. 2011;14(2): 113-23.

10. Katayama H, Kurokawa Y, Nakamura K, Ito H, Kanemitsu Y, Masuda N, et al. Extended Clavien-Dindo classification of surgical complications: Japan Clinical Oncology Group postoperative complications criteria. Surgery Today. 2016;46(6):668-85.

11. Schoenfeld DA, Richter JR. Nomograms for calculating the number of patients needed for a clinical trial with survival as an endpoint. Biometrics. 1982;38(1):163-70.

12. Oba K, Paoletti X, Alberts S, Bang YJ, Benedetti J, Bleiberg H, et al. Disease-free survival as a surrogate for overall survival in adjuvant trials of gastric cancer: a meta-analysis. J Natl Cancer Inst. 2013;105(21):1600-7.

13. Lan KK, DeMets DL. Discrete sequential boundaries for clinical trials. Biometrika. 1983;70(3):659-63.

14. Kitajima T, Shinohara H, Haruta S, Momose K, Ueno M, Udagawa $\mathrm{H}$. Prevention of transient liver damage after laparoscopic gastrectomy via modification of the liver retraction technique using the Nathanson liver retractor. Asian J Endosc Surg. 2015;8(4):413-8.

15. Shinohara T, Kanaya S, Yoshimura F, Hiramatsu Y, Haruta S, Kawamura $\mathrm{Y}$, et al. A protective technique for retraction of the liver during laparoscopic gastrectomy for gastric adenocarcinoma: using a Penrose drain. J Gastrointest Surg. 2011;15(6): 1043-8.

16. Yamada H, Kojima K, Inokuchi M, Kawano T, Sugihara K. Effect of obesity on technical feasibility and postoperative outcomes of laparoscopy-assisted distal gastrectomy-comparison with open distal gastrectomy. J Gastrointest Surg. 2008;12(6): 997-1004.

17. Lee HJ, Kim HH, Kim MC, Ryu SY, Kim W, Song KY, et al. The impact of a high body mass index on laparoscopy assisted gastrectomy for gastric cancer. Surg Endosc. 2009;23(11):2473-9.

18. Jung JH, Ryu SY, Jung MR, Park YK, Jeong O. Laparoscopic distal gastrectomy for gastric cancer in morbidly obese patients in South Korea. J Gastric Cancer. 2014;14(3):187-95.

19. Kim MC, Kim W, Kim HH, Ryu SW, Ryu SY, Song KY, et al. Risk factors associated with complication following laparoscopyassisted gastrectomy for gastric cancer: a large-scale Korean multicenter study. Ann Surg Oncol. 2008;15(10):2692-700.

20. Lee SE, Ryu KW, Nam BH, Lee JH, Kim YW, Yu JS, et al. Technical feasibility and safety of laparoscopy-assisted total gastrectomy in gastric cancer: a comparative study with laparoscopy-assisted distal gastrectomy. J Surg Oncol. 2009;100(5): $392-5$. 